\title{
DEMOCRACIA SIN DERECHOS En torno al Kelsen democrático
}

\author{
Anna Pintore \\ Universidad de Cagliari
}

\section{Kelsen democrático}

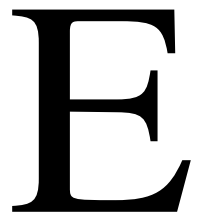

1 Kelsen democrático sigue estando oscurecido por el Kelsen teórico del Derecho, y en cualquier caso en general desatendido. Baste señalar que en los dos trabajos más importantes de los últimos diez años sobre las relaciones entre democracia y Estado de Derecho, Diritto e ragione de Luigi Ferrajoli y Faktizität und Geltung de Jürgen Habermas, sus ensayos sobre la democracia ni siquiera se mencionan ${ }^{1}$.

En realidad, al Kelsen teórico de la democracia no se le ha dedicado demasiada atención ni siquiera en el ambiente cultural que le debería haber sido más favorable: el de la filosofía jurídica y política de inspiración iuspositivista, analítica, laica y liberal. Ello, en mi opinión, no se debe sin embargo al hecho de que sus ideas hayan parecido equivocadas o, peor aún, irrelevantes, sino a que, al contrario, se han percibido como totalmente obvias y compartibles, al menos hasta tiempos recientes.

Esta sensación de obviedad y de compartibilidad ha impregnado los dos rasgos principales en torno a los cuales giran tales ideas, a saber: en primer lugar, la vinculación establecida entre democracia y relativismo ético; en segundo lugar, la definición de democracia como procedimiento.

Pues bien: me parece que esta impresión de obvia aceptabilidad de la teoría kelseniana de la democracia ha estado alimentada por dos equívocos: el que denominaré equívoco relativista y el que denominaré equívoco procedimentalista. El equívoco relativista lleva a considerar al relativismo éti-

1 Véase L. Ferrajoli, Diritto e ragione. Teoria del garantismo penale, Laterza, Roma-Bari, 1989; J. Habermas, Fatti e norme. Contributi a una teoria discorsiva del diritto e della democrazia (1992), trad. it. de L. Ceppa, Guerini e Associati, Milán, 1996.

La reciente (e imponente) literatura filosófico-política en lengua inglesa sobre el tema de la democracia ignora absolutamente a Kelsen. 
co como una buena justificación (cuando no la justificación por excelencia) de la democracia. El equívoco procedimentalista lleva a sostener que existe una categoría de definiciones meramente procedimentales de la democracia, a la cual cabe adscribir también la definición de Kelsen.

Me ocuparé de estos dos equívocos, y ello me dará la oportunidad de discutir si las ideas kelsenianas presentan hoy un interés sólo arqueológico o si, por el contrario, pueden aportar todavía alguna contribución útil al debate contemporáneo sobre la democracia. Dichas ideas aún vienen considerándose «una piedra angular de la teoría contemporánea de la democracia»², pero hay que preguntarse hasta qué punto tal diagnóstico es correcto. De hecho, hoy la teoría de la democracia es esencialmente teoría de la democracia constitucional, y teoría dedicada al problema crucial de la conciliación entre derechos y soberanía popular ${ }^{3}$. Ese problema permaneció sin embargo, en lo sustancial, ajeno a los horizontes de Kelsen, quien elaboró, ciertamente, una teoría de la constitución, y elaboró además una teoría de la democracia, pero nunca vinculó ambas en una teoría de la democracia constitucional (o, si se prefiere, del constitucionalismo democrático). En este sentido, su contribución a la teoría de la democracia debe considerarse hoy en día algo desfasada, cuando no claramente obsoleta. Sin embargo, creo que todavía merece prestarle mucha atención, ya que en los escritos de Kelsen está implícito un modelo que podría denominarse provocativamente de $d e$ mocracia sin derechos, un modelo que puede desempeñar una función de saludable contrapeso frente a los modelos de democracias saturadas de derechos actualmente predominantes.

\section{Democracia y relativismo ético}

Hablemos ya del equívoco relativista. Como es sabido, uno de los dos principales argumentos justificativos de la democracia recurrentes en los escritos filosófico-políticos de Kelsen se refiere precisamente al nexo entre democracia y relativismo filosófico ${ }^{4}$. Kelsen nos dice que sólo quien adop-

\footnotetext{
${ }^{2}$ G. Zagrebelski,, Il «crucifige!» e la democrazia, Einaudi, Torino, 1995, p. 119.

${ }^{3}$ Recuérdese de nuevo a este respecto Facticidad y validez de J. Habermas. En lengua inglesa, una defensa entre las más persuasivas del modelo democrático-constitucional se encuentra en S. Holmes, Passions and Constraints. On the Theory of Liberal Democracy, The University of Chicago Press, Chicago \& London, 1995. En Italia el trabajo reciente más significativo sobre el tema es: G. Palombella, Costituzione e sovranità. Il senso della democrazia costituzionale, Dedalo, Bari, 1997.

${ }^{4} \mathrm{El}$ otro argumento es el que se remite al valor de la autonomía. Sobre el tema, léanse las perspicuas consideraciones de S. Paulson, «Kelsen as Political Theorist, in La Pensée politique de Hans Kelsen», en Cahiers de Philosophie Politique et Juridique, n. 17, Centre de Publications de 1'Université de Caen, Caen, 1990, pp. 81-95.
} 
ta, en ética y en filosofía, una actitud relativista, puede tratar la democracia como un valor y defenderla genuinamente.

«Relativismo filosófico» es sin embargo una expresión no unívoca en el léxico de Kelsen, ya que es usada por él para indicar al menos tres tesis diferentes: una tesis gnoseológica, una tesis metaética, y una tesis ética.

En primer lugar, esta expresión es empleada por él para indicar un complejo de asunciones gnoseológicas, que hoy podrían designarse como empirismo, no cognoscitivismo y constructivismo (moderado). Empirismo, o sea: el conocimiento es siempre sólo conocimiento empírico ${ }^{5}$; no cognoscitivismo, o sea: sólo los hechos pueden ser objeto de conocimiento y no los valores, por lo que verdad y justicia son atributos radicalmente heterogéneos $^{6}$; constructivismo, o sea: el conocimiento es siempre relativo al sujeto que lo produce ${ }^{7}$.

En segundo lugar, «relativismo filosófico» es una expresión empleada por Kelsen para indicar un complejo de tesis éticas. En sus escritos sobre la democracia Kelsen no tematiza la distinción entre ética y metaética, y por tanto no aclara si, cuando habla de relativismo, hace referencia a una tesis ética sustantiva (los valores son relativos a quien los adopta) o bien a una tesis metaética (no existe un fundamento objetivo de los valores). Sostengo que los dos aspectos están presentes conjuntamente en el relativismo filosófico por él delineado. «Relativismo filosófico» indica por tanto, por un lado, la tesis metaética según la cual los valores no son inmanentes a la realidad y no pueden ser extraídos de ella a través del conocimiento racional: no objetivismo ético ${ }^{8}$; por otro lado, la tesis ética según la cual los valores son relativos a los individuos que los adoptan: relativismo normativo 9 .

Entre democracia y relativismo Kelsen establece una multiplicidad de conexiones situadas en planos diversos.

${ }^{5}$ H. Kelsen, Essenza e valore della democrazia, pp. 147-8; Id., I fondamenti della democrazia, p. 222ss.

${ }^{6} \mathrm{H}$. Kelsen, I fondamenti della democrazia, pp. 223-4.

${ }^{7} \mathrm{H}$. Kelsen, I fondamenti della democrazia, pp. 224-6.

${ }^{8}$ H. Kelsen, I fondamenti della democrazia, pp. 270-1. Obviamente, el aspecto metaético y el gnoseológico del relativismo filosófico se entrecruzan, en el momento en que las tesis gnoseológicas se refieren a los valores: el no cognoscitivismo es el componente (gnoseológico) de una metaética (usualmente no objetivista).

${ }^{9}$ H. Kelsen, I fondamenti della democrazia, pp. 269. La expresión «relativismo normativo» es de W.K. Frankena, Etica. Un'introduzione alla filosofia morale (1973), trad. it. de M. Mori, Comunita, Milán, 1981, p. 207ss. Frankena distingue del relativismo nornativo el relativismo descriptivo y el metaético. 
En primer lugar, un nexo de carácter psicológico ${ }^{10}$. Para Kelsen no hay solución de continuidad entre relativismo, sea gnoseológico o ético/metaético, y personalidad tolerante; y, viceversa, entre absolutismo y personalidad totalitaria, autocrática.

En segundo lugar, un nexo de carácter histórico: «casi todos los mayores exponentes de la filosofía relativista fueron políticamente partidarios de la democracia, mientras que los seguidores del absolutismo filosófico, los grandes metafísicos, fueron partidarios del absolutismo y contrarios a la democracia» ${ }^{11}$.

Junto a estas conexiones de orden fáctico, psicológico o histórico, Kelsen establece otro género de ligamen entre democracia y relativismo. No se trata, dice, de un nexo «necesariamente lógico», sino más bien de una «relación de congenialidad» ${ }^{12}$; de una «íntima relación», de una «coordinación $»^{13}$ tal, que se debe admitir que el relativismo es el presupuesto de la democracia ${ }^{14}$ : «si yo me pronuncio a favor de la democracia, lo hago exclusivamente (...) a causa (...) del ligamen que existe entre una democracia y una teoría relativista ${ }^{15}$. Kelsen, a decir verdad, no trata al relativismo como condición suficiente, pero ciertamente lo trata como condición necesaria de la justificación de la democracia. Y, en todo caso, el nexo que él postula no tiene naturaleza puramente fáctica y contingente; tampoco parece tener, sin embargo, carácter necesario e inmanente («necesariamente lógico»): en este sentido, se podría aproximar al nexo que liga a una aserción con sus presuposiciones pragmáticas, las cuales no pueden negarse sin hacer paradójica la aserción misma. Es aquí pertinente, obviamente, el conocido y paradójico ejemplo de Strawson: «llueve, pero no lo creo»; tal afirmación no es en sí lógicamente contradictoria, pero es «extraña» porque viola la regla pragmática que obliga a afirmar sólo proposiciones coherentes con las actitudes proposicionales del emisor. Ahora bien, parecería que Kelsen considerase análogamente paradójico, aunque no contra-

${ }^{10} \mathrm{H}$. Kelsen, I fondamenti della democrazia, p. 243: aquí Kelsen habla de «paralelismo» entre absolutismo filosófico y político.

${ }^{11} \mathrm{H}$. Kelsen, I fondamenti della democrazia, p. 259ss.

${ }^{12}$ H. Kelsen, I fondamenti della democrazia, p. 274.

${ }^{13}$ H. Kelsen, I fondamenti della democrazia, p. 219.

${ }^{14}$ H. Kelsen, Essenza e valore de la democrazia, p. 149: «el relativismo es la concepción del mundo que la idea democrática supone».

${ }^{15} \mathrm{H}$. Kelsen, Essenza e valore de la democrazia, p. 138. No se ve sin embargo cómo, para un divisionista como Kelsen, el relativismo epistemológico y gnoseológico puedan influir sobre la ética/metaética. El discurso que sigue se limitará a tomar en consideración los nexos entre democracia y relativismo ético y metaético. 
dictorio, afirmar: «La democracia es un valor, pero yo no creo en la fundamentación de los valores» ${ }^{16}$.

Sea como fuere, las ideas kelsenianas sobre las implicaciones democráticas del relativismo no podían sino gustar al positivismo jurídico, especialmente al analítico, el cual leía en ellas, en el plano metaético, una reafirmación de la ley de Hume (los valores no se pueden fundamentar sobre los hechos); mientras que, en el plano de la ética sustantiva, veía en ellas una manifestación de su propio espíritu laico, pluralista y tolerante.

Sin embargo, por su relativismo democrático, Kelsen ha sido más criticado (por sus adversarios) que elogiado (por sus partidarios). Las críticas, a decir verdad, se han mantenido simétricas a los argumentos criticados, en el sentido de que han reproducido exactamente ese orden de ideas, sólo que dándoles la vuelta. Igual que Kelsen afirmaba el nexo entre relativismo y democracia, los críticos lo negaban oponiéndole uno de signo contrario: no entre relativismo (metaético y ético) y democracia, sino entre objetivismo o verdad de los valores y democracia. Igual que Kelsen sostenía que una visión absolutista de los valores podía poner en peligro la fe en la democracia, así sus críticos le oponían que los peligros para la (justificación de) la democracia derivan precisamente del relativismo, y solo pueden evitarse desde una perspectiva ética objetivista: si no afirmamos la verdad de los valores, el poder queda abandonado a la pura fuerza, aunque sea la fuerza de la mayoría, y se presta un flaco servicio a la democracia, que no queda justificada sino al contrario, debilitada.

Encuentro desconcertante que nunca se haya dicho, como crítica a Kelsen y a los críticos de Kelsen, que ambos se equivocan totalmente.

Se equivoca Kelsen, cuando afirma: «que los juicios de valor tengan una validez sólo relativa -principio basilar del relativismo filosófico- implica que juicios de valor opuestos no estén excluidos ni lógica ni moralmente» ${ }^{17}$.

En efecto, él confunde así el fundamento con el contenido de los juicios de valor ${ }^{18}$ : una cosa es qué valores se adoptan, y otra cosa es si esos valores tienen o no un fundamento, y qué tipo de fundamento tienen. La admisibilidad de puntos de vista y de valores en competencia no procede de una respuesta negativa al problema de la fundamentación de los valores, como sostiene Kelsen, sino que procede exclusivamente del tipo de valores que sean abrazados y defendidos. Por decirlo de otro modo, se puede perfectamente

\footnotetext{
${ }^{16} \mathrm{O}$ bien, en la versión del relativismo normativo: «La democracia es un valor, pero es un valor relativo a mí que lo adopto».

${ }^{17}$ H. Kelsen, I fondamenti della democrazia, p. 269.

${ }^{18}$ Sobre esta distinción, precisamente en relación con el relativismo ético, véase A. Ross, Direttive e norme (1968), trad. it. de M. Jori, Comunita, Milán, 1978, p. 125.
} 
ser relativista (o sea, no objetivista) en ética, y al mismo tiempo defender valores que «excluyan moralmente juicios de valor opuestos»; y viceversa, se puede perfectamente ser absolutista (o mejor dicho, objetivista), y al mismo tiempo admitir la legitimidad moral de puntos de vista opuestos.

«El relativismo es una teoría metaética, y su verdad o falsedad es cuestión que compete a un observador externo. Defender la tolerancia o ser tolerantes son actividades internas a sistemas morales particulares -actividades de participantes. No hay nada que el relativista qua relativista pueda decir a favor o en contra de la tolerancia desde un punto de vista moral. En el momento en que lo haga deja de ser un observador de la moral y se convierte en un usuario de un sistema moral» ${ }^{19}$.

Una cosa es el fundamento, y otra el contenido. No hay diferencia alguna en que la tolerancia, por ejemplo, se defienda desde una perspectiva objetivista o desde una perspectiva no objetivista ${ }^{20}$. Cierto es que quien parte de la creencia en la validez objetiva de los (sus) valores tendrá la propensión psicológica a sostener que éstos se deben imponer o que sean impuestos en detrimento de los valores contrarios ${ }^{21}$, pero esto no implica necesariamente una actitud imperialista o intolerante. De hecho, el valor que se considera verdadero y que se desearía imponer bien pudiera ser precisamente el valor de la tolerancia, y por tanto de la admisibilidad simultánea de puntos de vista opuestos ${ }^{22}$. Por la otra parte, el relativismo, entendido como posición ética sustantiva, ya no es congenial ni con la tolerancia ni con la intolerancia: el relativista ético defiende sus propios valores, si es que los defiende, exactamente como lo hace el absolutista ${ }^{23}$.

\footnotetext{
${ }^{19}$ G. Harrison, «Relativism and Tolerance», en P. Laslett, J. Fishkin (eds.), Philosophy, Politics and Society, Fifth Series, Blackwell, Oxford, 1979, p. 286. En el mismo sentido, F. Oppenheim, «Relativism, Absolutism, and Democracy», en The American Political Science Review, 1950, pp. 951-960.

${ }^{20}$ En sentido distinto, J. Maritain, Tolleranza e verità (1957), en Il filosofo nella società, trad. it. de A. Pavan, Brescia, 1976, p. 67, polemizando con Kelsen, observa que «no hay tolerancia real y auténtica sino cuando un hombre está firme y absolutamente convencido de una verdad, o de lo que él sostiene como una verdad, y cuando, al mismo tiempo, reconoce a quienes niegan esa verdad el derecho a existir y a contradecirle, no porque éstos sean libres en relación con la verdad, sino porque buscan a su modo la verdad y porque él respeta en ellos la naturaleza humana y la dignidad humana».

${ }^{21}$ Por tanto, con la reserva enseguida señalada en el texto, se puede concluir que el nexo más prometedor entre relativismo y tolerancia de los tres indicados por Kelsen es si acaso el de tipo psicológico.

${ }^{22}$ Véase A. Spadaro, Contributo per una teoria della costituzione, I. Fra democrazia relativista e assolutismo etico, Giuffrè, Milán, 1994, esp. p. 278: «La tolerancia debe fundarse no tanto sobre el presupuesto de que 'nadie' está en situación de conocer la verdad (o fragmentos de la misma), cuanto sobre la idea (...) de que nadie puede imponer su (presunta) verdad».

${ }^{23}$ Kelsen recuerda la bella frase de Schumpeter: «Lo que distingue a un hombre civilizado de un bárbaro es el darse cuenta de la validez relativa de sus propias convicciones y, a pesar de ello, sostenerlas sin echarse atrás» (H. Kelsen, I fondamenti della democrazia, p. 198).
} 
La distinción entre tolerancia e intolerancia y entre defensa y crítica de la democracia no pasa, pues, por la cuestión de la fundamentación sino por la del contenido de los valores. Ella depende del hecho de que en nuestra ética acojamos o no metavalores liberales, como los de tolerancia, autonomía, neutralidad o imparcialidad, sean éstos concebidos o no como dotados de fundamento objetivo. Por eso Kelsen se equivoca cuando afirma que «la tolerancia presupone la relatividad de la verdad sostenida o del valor postulado, y tal relatividad implica que la verdad o el valor contrario no esté completamente excluido» ${ }^{24}$.

Kelsen se equivoca pues al establecer un nexo fuerte entre relativismo y democracia. La verdad práctica carece de influencia sobre la democracia y su justificación: tanto quien crea en su existencia como quien no lo crea puede argumentar coherentemente tanto a favor como en contra de la democracia $^{25}$.

En particular, la democracia puede ser defendida (y es notorio que ha sido defendida) también desde una perspectiva objetivista, por ejemplo con argumentos de carácter naturalista, como los que insisten en las cualidades veritativas de las decisiones por mayoría ${ }^{26}$; o bien con argumentos de carácter teleológico, como los que tratan el método democrático como el que, a la larga, favorece el descubrimiento de la verdad ${ }^{27}$.

Si Kelsen se equivoca, se equivocan también sus críticos, desde el momento en que replican a su tesis pero le oponen otra viciada por el mismo error, argumentando que la democracia puede ser adecuadamente justificada y defendida sólo a partir de valores objetivos, es decir, valores objetivamente fundamentados y objetivamente superiores a los valores opuestos. El discurso poco antes expuesto sobre la irrelevancia del relativismo (ético y metaético) vale de hecho plenamente, mutatis mutandis, para lo que Kelsen

\footnotetext{
${ }^{24}$ H. Kelsen, I fondamenti della democrazia, p. 321.

${ }^{25}$ Sobre este punto, véanse los excelentes argumentos de R. Harrison, La democrazia é un bene?, trad. it. de M. A. Bogdanovic, Ecig, Génova, 1996, cap. IX.

${ }^{26}$ J.H. Hallowell, Il fondamento morale della democrazia, trad. it. de M. Sallusti, Giuffrè, Milán, 1995, p. 140: «estamos obligados a someternos a la decisión de la mayoría no porque ésta represente una voluntad numéricamente superior, sino porque es manifestación del mejor juicio de la sociedad con referencia a una materia concreta en un momento determinado». Hallowell cita a Aristóteles, Política, III, 11.2-3: «Puede ocurrir en efecto que los muchos, aun no siendo individualmente excelentes, cuando se reúnen juntos, sean superiores [...] En realidad, siendo muchos, cada uno tiene una parte de virtud y de prudencia, y como cuando se reúnen juntos, en masa, se convierten en un hombre con muchos pies, con muchas manos, con muchos sentidos, se convierten así en un hombre con muchas y excelentes dotes de carácter y de inteligencia. Por tal motivo los muchos juzgan mejor».

${ }^{27}$ J.S. Mill, Considerazioni sul governo rappresentativo (1861), trad. it. de M. Prospero, Editori Riuniti, Roma, 1997, p. 40 ss.
} 
llama absolutismo ético, y que nosotros podemos llamar objetivismo y cognoscitivismo. La convicción, en el plano metaético, de que sea posible una fundamentación objetiva (racional, empírica o metafísica) de los valores, no aporta ningún argumento ni a favor ni en contra de la democracia (o de la tolerancia, por permanecer en el orden de ideas de Kelsen): simplemente, porque no dice nada sobre el valor (o disvalor) sustantivo de la democracia; sólo dice que se puede demostrar que los valores que nosotros ligamos a la democracia son verdaderos o falsos. Eso es todo.

También en el caso del objetivista, todo depende de los valores sustantivos adoptados: si el objetivista en cuestión sostiene que los valores verdaderos son la autonomía, la tolerancia, el respeto a las minorías, etc., su ética democrática será sustantivamente idéntica a la kelseniana. La única diferencia será que él la cree verdadera, a diferencia de Kelsen.

No obstante, hay que señalar que el objetivista se encuentra ante a una complicación que es extraña a la posición de un no objetivista à la Kelsen. Mientras que, en efecto, este último, dado que excluye de su horizonte los valores objetivos, resuelve -obviamente in limine- el problema de su (re)conocibilidad negando que tenga sentido incluso planteárselo, el objetivista se encuentra en el deber de afrontar este ulterior problema: no sólo debe demostrar que existen valores verdaderos, sino que los que él sostiene efectivamente lo son. Dicho con otras palabras, una cosa es sostener que es posible fundamentar objetivamente los valores, y otra cosa es demostrar que los valores que uno prefiere son de verdad los correctamente fundamentados, y no fruto de errores o algo parecido. No basta, evidentemente, creer en la ética verdadera para atribuir una patente de verdad a nuestra propia ética ${ }^{28}$.

Así pues, los problemas de fundamentación de la ética son en conjunto irrelevantes para la democracia. Esta conclusión podrá desilusionar a aquellos que dicen poder derivar la ética democrático-liberal, y los valores de laicismo, tolerancia, etc., precisamente de la opción por una metaética no objetivista y divisionista. Dicha conclusión podría ser tomada sin más como una «traición» a la metaética analítica.

Pero, bien mirado, las cosas no son así. Una de las principales enseñanzas que uno de los maestros de la filosofía analítica, Uberto Scarpelli, nos ha dejado en herencia se refiere precisamente a las relaciones entre metaética y ética, y puede sintetizarse como el principio de prioridad de la ética sobre la metaética. Dicho principio afirma que la metaética no puede fun-

\footnotetext{
${ }^{28} \mathrm{Y}$ sin embargo es irresistible la tentación de dar este paso de la metaética objetiva a la ética verdadera. Es en este plano psicológico en el que se insinúan y se concentran las pretensiones imperialistas del objetivista.
} 
damentar a la ética, y que es en cambio la ética la que ha de justificar a la metaética. No podemos justificar la democracia con una metaética, por la sencilla razón de que ningún valor o sistema de valores sustantivos puede ser justificado, en cuanto a su contenido, por una metaética, cualquiera que ésta sea, sino únicamente por otros valores sustantivos; son precisamente estos últimos los que han de conducirnos a elegir un tipo de metaética con preferencia sobre otro. La metaética, desde esta perspectiva, no desempeña un papel de justificación (sobre el contenido), sino de fundamento [fondazione] de los valores ${ }^{29}$ : nos dice cuál es su status ontológico y epistemológico, su radicación en la realidad natural y social, nos proporciona la sintaxis.

\section{La democracia kelseniana como procedimiento. ¿En qué sentido?}

Pasemos ahora al «equívoco procedimentalista». En la literatura filosófico-política al uso es habitual encontrarse con la contraposición entre dos concepciones de la democracia (o entre dos definiciones del término «democracia»): una concepción o definición procedimental, y una concepción o definición que, a falta de un nombre mejor, provisionalmente se podría llamar sustantiva. La primera concepción o definición suele habitualmente ligarse, además de al nombre de Kelsen, a los nombres de Schumpeter, de Dahl, de Popper, de Bobbio, y calificarse de concepto «mínimo», «restringido» $\mathrm{o}$ «formal» $»^{30}$ (o, en el lenguaje de sus detractores, «formalista» $\left.{ }^{31}\right)$, procedimental o procedimentalista ${ }^{32}$ de democracia.

Kelsen califica la democracia como un «método político», habla de «elemento procedimental»o «procedimiento», y afirma que «como método o procedimiento, la democracia es una 'forma' de gobierno» ${ }^{33}$, pero en realidad se detiene poco a discutir de estos rasgos de su definición de democracia, así como de los nexos entre esta última y el relativismo filosófico del

${ }^{29}$ U. Scarpelli, «La meta-etica analitica e la sua rilevanza etica», en L'etica senza verità, Il Mulino, Bologna, 1982, pp. 106-7: «'Fundamentar' [Fondare] significa inyectar los cimientos de un edificio en un terreno sólido capaz de sostenerlo, o, en filosofía, hallar y poner en claro la razón suficiente; y corresponde a lo teorético. 'Justificar' [Giustificare] significa en cambio mostrar, o constituir, la legitimidad, la corrección, la medida [giustezza] de ciertas operaciones en un contexto de directivas y valores; y corresponde a lo ético».

${ }^{30} \mathrm{~N}$. Bobbio, Il futuro della democrazia. Una difesa delle regole del gioco, Einaudi, Torino, 1984, p. X, donde se habla de «definición mínima», «procedimental» o «formal» de democracia.

${ }^{31}$ R. Porciello, «Le concezioni 'formalistiche' della democrazia in Kelsen e Popper. Problemi e prospettive critiche», en Coscienza, 1991, p. 13ss. P. Barcellona, Il declino dello stato. Riflessioni di fine secolo sulla crisi del progetto moderno, Dedalo, Bari, 1998, p. 166, habla de «formalismo procedimental».

${ }^{32}$ G. Pecora, Il pensiero politico di Hans Kelsen, Laterza, Roma-Bari, 1995, pp. 8-9.

${ }^{33}$ H. Kelsen, I fondamenti della democrazia, respectivamente en las pp. 196 y 198. 
que se ha discutido poco antes. Se puede no obstante reconstruir fácilmente esos nexos: dado que los valores son relativos y no susceptibles de fundamentación, la democracia puede justificarse únicamente si no se define en términos de valores y contenidos (necesariamente controvertidos), sino en términos de procedimientos (exentos de valores o contenidos) ${ }^{34}$. Ello, según los críticos, conduciría a relegar la esfera pública a la irrelevancia ética y, en última instancia, a abandonarla a la fuerza de los más ${ }^{35}$; según los defensores, conduce a suplir, con un método decisional en sí mismo digno de valor, una razón que es deficitaria en el terreno de los asuntos prácticos ${ }^{36}$.

Cuando hablamos de democracia procedimental o de definición procedimental de democracia, debemos antes que nada preguntarnos qué entendemos por «procedimiento». Método, forma, formalismo, son nociones demasiado comprometidas filosóficamente y en todo caso demasiado elusivas para poder tratarlas como sinónimos satisfactorios de «procedimiento».

En la versión de Bobbio, «democracia procedimental» significa que el concepto de democracia nos da (y debe limitarse a darnos) simplemente las reglas del juego, o sea, las reglas sobre quién está autorizado a decidir (competencias) y sobre cómo decidir (procedimiento) ${ }^{37}$. Y sin embargo esta distinción entre el quién y el cómo, por un lado, y el qué, por el otro, por más que resulte intuitiva, presenta rasgos de incerteza que han de ser aclarados.

Discutiendo en general sobre las tendencias procedimentalistas de las teorías de la justicia contemporáneas, se ha dicho que «el procedimentalismo acentúa la distinción entre principios morales de primer y de segundo orden ${ }^{38}$. Esta caracterización merece sin duda ser admitida, pero creo que es todavía insuficiente, ya que remite a una ulterior noción que es a su vez equívoca. En efecto, de principios morales de segundo orden se puede hablar en al menos dos sentidos diferentes.

En un primer sentido, se puede hablar de ellos como de principios cuyo contenido remite al contenido de otros principios o normas de conducta mo-

${ }^{34}$ En realidad el nexo, en mi opinión, se refiere sólo a lo que Frankena llama relativismo descriptivo; como acertadamente asume Rawls, cuando trata como motivo fundamental de la democracia el hecho del ineliminable pluralismo ético y religioso. Véase J. Rawls, Liberalismo Politico (1993), trad. it. de G. Rigamonti, Comunita, Milán, 1994, pp. 47, 69, 125, 186.

${ }^{35}$ Véase V. Possenti, «Democrazia e filosofia: le aporie della fondazione della democrazia in Kelsen», en Persona y Derecho, 1991, p. 195: la doctrina kelseniana «configura una democracia procedimental fundamentalmente sin finalidad, un perímetro disponible para contenidos diferentes».

${ }^{36}$ Sobre el procedimiento entendido como sustituto de la razón práctica y de la verdad, véase mi Il diritto senza verità, Giappichelli, Turín, 1996, cap. VI.

${ }^{37}$ N. Bobbio, Il futuro della democrazia, p. 4.

${ }^{38}$ Así, S. Chambers, Reasonable Democracy. Jürgen Habermas and the Politics of Discourse, Cornell University Press, Ithaca \& London, 1996, p. 17. 
ral. Por ejemplo, pueden considerarse tales la tolerancia, o la neutralidad, o la imparcialidad, por el hecho de que, para ser empleados, deben «apoyarse» sobre o completarse a través de el reenvío a otros valores o reglas morales, respecto de las cuales se sitúan en un plano metalingüístico o lógicamente superior. Por ejemplo, el principio de la tolerancia establece, digamos, que debemos tolerar los valores morales distintos de los nuestros: de modo que, para que este principio nos pueda proporcionar una guía autosuficiente de conducta, tenemos la necesidad de hacer referencia a otros valores (los valores distintos de los nuestros y los opuestos a los nuestros). En este sentido la tolerancia es un metavalor: nos suministra una guía para la acción, pero esta guía es incompleta hasta que no la integremos con los valores de primera instancia. Si queremos encontrar en el Derecho un análogo de este tipo de principios morales de segunda instancia, podemos acudir a las normas de Derecho internacional privado que llevan a cabo un reenvío recepticio a normas pertenecientes a otro ordenamiento.

En un segundo sentido, podemos hablar de principios morales de segundo nivel como de principios que no nos dicen nada sobre cómo actuar de modo moralmente recto, y por tanto no nos proporcionan directamente «instrucciones» morales (sean éstas completas o incompletas), sino que se limitan a indicarnos el modo de identificar los principios para obrar de modo moralmente recto ${ }^{39}$. Podremos por tanto llamar procedimentales a aquellos principios que no especifican (ni siquiera de modo incompleto) el contenido de los valores a adoptar o de las normas a seguir, sino que solamente indican los criterios de elección de las normas y de los valores, criterios que no contienen referencia alguna al contenido de las normas y de los valores que habrán de ser preferidos, sino sólo una remisión a la fuente, por decirlo así, de la cual obtenerlos. El análogo jurídico de tales principios morales sería el de las normas de Derecho internacional privado que llevan a cabo un reenvío no recepticio a fuentes jurídicas de otro ordenamiento.

Así pues, la peculiaridad de las éticas procedimentales en el sentido aquí indicado no es tanto el estar vacías de contenidos (el ser «formales»), cuanto el proporcionar una guía de conducta exclusivamente indirecta, ya que comprenden únicamente normas de segunda instancia, y han de ser completadas con la elección de las normas de conducta de primera instancia, elección que ha de llevarse a cabo siguiendo precisamente los modos indicados como procedimiento. En este sentido, una ética procedimental es parangonable con un ordenamiento jurídico compuesto exclusivamente por

\footnotetext{
${ }^{39}$ Este «identificar» [individuare] podrá leerse como un decidir, o como un descubrir, según se adopte una perspectiva no cognoscitivista o una perspectiva cognoscitivista, respectivamente.
} 
metanormas sobre la producción jurídica ${ }^{40}$ : podría ser el caso (completamente imaginario, como es obvio) de un ordenamiento recién nacido a raíz de una revolución jurídica, y formado únicamente por la regla de reconocimiento que regula las modalidades de creación de las demás normas, de momento aún no creadas.

El procedimiento así concebido puede ser un procedimiento hipotético o real. En el primer caso, las derivaciones de los principios procedimentales se obtienen a través del experimento mental constitutivo del procedimiento, o sea, mediante un puro razonamiento. El ejemplo celebérrimo de procedimiento hipotético en este sentido es el representado por el método decisional seguido por los contratantes situados en la posición originaria, método ilustrado por Rawls en su Teoría de la Justicia. En el segundo caso, las derivaciones de los principios procedimentales se vinculan a la efectiva verificación en el mundo empírico de acontecimientos o comportamientos, considerados por los principios procedimentales como hechos o actos productores de reglas sustantivas. Éste es exactamente el caso de la democracia política, que puede por tanto definirse como «un conjunto de reglas de procedimiento para la formación de decisiones colectivas» ${ }^{41}$.

Si la anterior es una buena caracterización de los principios procedimentales, de ella se deriva que hablar de «procedimiento» como sinónimo de «forma» acaba siendo engañoso, porque cualquier principio moral, a menos que se trate de una mera tautología, tiene obviamente un contenido. Así también los principios procedimentales tienen contenidos normativos y valorativos, si es que los procedimientos no se indican de un modo totalmente vacuo.

Cuando se dice que la democracia procedimental es también (por ello mismo) formal, o sea, carente de contenidos, se está usando, queriéndolo o no, una fórmula equívoca. La equivocidad radica en no distinguir entre los contenidos del método (digámoslo así) y los contenidos derivados de la aplicación del método. El método, por decirlo como Bobbio, nos indica el quién y el cómo, y son precisamente éstos sus contenidos. El «quién» podría concretarse en «los mayores de edad», «los notables», «los propietarios», etc. $\mathrm{El}$ «cómo» podría ser un sorteo, una votación, etc. Precisamente éstos son los contenidos del procedimiento. Y es obvio que estos contenidos pueden ser juzgados iuxta propria principia, por su valor (o disvalor),

${ }^{40}$ J. Habermas, Morale, diritto, politica, trad. it. de L. Ceppa, Einaudi, Torino, 1992, pp. 16-17, no por casualidad alude, hablando de éticas procedimentales, a la teoría hartiana de las normas secundarias.

${ }^{41}$ N. Bobbio, Il futuro della democrazia, p. X. 
sea intrínseco o instrumental ${ }^{42}$. En este sentido, es obvio que los procedimientos nunca son irrelevantes o moralmente neutros, en la medida en que son constitutivos del juego al que se está jugando: son valores (o disvalores) que pueden y deben ser apreciados en sí, también porque pueden contribuir a redefinir los fines a los que sirven: vale aquí el dicho inglés garbage in garbage out ${ }^{43}$. De aquí se deriva que el universo del procedimentalista no está vacío de valores y relegado a la irrelevancia ética, como querrían hacernos creer sus críticos.

Kelsen era bien consciente de este aspecto ambivalente de los procedimientos democráticos, como se ve en la siguiente cita: «no obstante, si la democracia es sobre todo una forma, de Estado o de gobierno, se debe tener presente que el antagonismo entre forma y sustancia o entre forma y contenido es solamente relativo, y que una misma cosa puede parecer forma desde un punto de vista y contenido o sustancia desde otro» ${ }^{44}$.

Cuestión distinta de la de los contenidos de las reglas procedimentales en sí mismas consideradas, es la de los contenidos de las reglas producidas mediante la correcta aplicación de los procedimientos, y la de la relación entre estas últimas reglas y las reglas procedimentales mismas. Respecto a tal relación, nos encontramos frente a la siguiente, bien conocida, alternativa: si la democracia ha de entenderse como un método que puede llevar a

${ }^{42}$ Véase C. J. Peters, «Adjudication as Representation», en Columbia Law Review, 1997, pp. 312-436, esp. p. 323ss., quien distingue entre un procedimentalismo deontológico, que valora el método democrático en sí mismo, por ejemplo kantianamente o rousseaunianamente como expresión de la autonomía, y un procedimentalismo consecuencialista, que lo valora en vistas a sus resultados. En general, sobre la distinción entre justificaciones intrínsecas e instrumentales de la democracia, véase C. Cohen, «The Justification of Democracy», en The Monist, 1, 55, 1971, pp. 1-28, p. 1ss.

${ }^{43}$ El brutal pero realista dicho es empleado por Rawls, «Reply to Habermas», en The Journal of Philosophy, 1995, p. 178, precisamente para ilustrar la relación entre los procedimientos y sus resultados.

Este punto ha sido subrayado eficazmente por G. Kateb, Remarks on the Procedures of Constitutional Democracy, en J.R. Pennock, J.W. Chapman (eds.), Constitutionalism, Nomos XX, New York University Press, New York, 1979, p. 215ss.

Pero, incluso antes, N. Bobbio, Quale socialismo? Discusione di una alternativa, Einaudi, Torino, 1976, p. 44ss., observaba: «no sólo los resultados son evaluables sobre la base de criterios que nos permiten distinguir resultados deseables de resultados no deseables, sino que también los procedimientos son susceptibles de juicios de valor, por lo cual es posible distinguir entre procedimientos buenos en sí mismos y procedimientos malos en sí mismos independientemente de sus resultados».

${ }^{44}$ H. Kelsen, I fondamenti della democrazia, p. 198 (cursiva del autor); y añade: «en particular, no existe ningún principio objetivo que establezca una diferencia entre el valor de una y el valor del otro. Para algunos efectos puede ser más importante la forma y, para otros, el contenido o la sustancia». 
elegir reglas con cualquier contenido, o bien sólo reglas con determinados contenidos ${ }^{45}$.

El tema de los límites de la democracia será abordado dentro de poco, de modo muy conciso, se entiende, dados los límites de esta ponencia. De momento, quiero subrayar que en ambos casos la democracia ha de ser entendida (al menos) como procedimiento, y que por tanto la distinción entre definiciones procedimentales y definiciones no procedimentales de democracia carece de fundamento. Una definición de «democracia» que no incluyese alguna referencia al método decisional se colocaría fuera del campo semántico que ha connotado la historia de esta palabra, tanto en sus acepciones antiguas como en las modernas ${ }^{46}$. Respecto a estas últimas, Bobbio afirma sin medias tintas: «quien no se haya dado cuenta de que por sistema democrático hoy se entiende de entrada un conjunto de reglas procedimentales en el cual la regla de la mayoría es la principal aunque no la única, no ha entendido y sigue sin entender nada de la democracia ${ }^{47}$. En este sentido, incluso la caracterización del concepto de democracia como essentially contested concept es en mi opinión inapropiada ${ }^{48}$. 'Democracia' es un

${ }^{45}$ En el primer caso, la democracia sería un ejemplo de lo que Rawls llama procedimiento puro (cualquier resultado al que conduzca es justo); en el segundo caso, sería un ejemplo de lo que Rawls llama procedimiento perfecto o imperfecto (según que realice siempre, infaliblemente, el fin al que tiende, o bien esté expuesto a fracasos). Véase J. Rawls, Una teoria della giustizia (1972), trad. it. de U. Santini, Feltrinelli, Milano, 1982, p. 85ss. No estoy segura, sin embargo, de que las dos distinciones -entre medios y fines, y entre procedimientos y contenidos (derivados de la aplicación de los procedimientos)- puedan superponerse y hacerse coincidir, como hace Rawls. Por el contrario, se podría distinguir entre los contenidos y los fines; si los contenidos no están predeterminados, los fines en cambio podrían estarlo. La democracia podría ser entendida cabalmente como un método que no determina de antemano los contenidos de las normas, y que sin embargo, como procedimiento, realiza puntualmente sus fines, por ejemplo, el fin de la autonomía, o el de la igualdad (¿en este caso se debería quizá hablar de procedimiento puro-perfecto?), o bien que realiza sus fines pero está expuesta a fracasos (¿en este caso se debería quizá hablar de procedimiento puro-imperfecto?).

${ }^{46}$ Así, se sitúa en mi opinión totalmente fuera del campo semántico de «democracia» la definición de «democracia sustantiva» ofrecida por L. Ferrajoli, Diritto e ragione, p. 904ss.: «Llamaré democracia sustantiva o social al 'estado de derecho' dotado de garantías efectivas, tanto liberales como sociales». La democracia sustantiva de Ferrajoli es en realidad estado de derecho, no democracia. Comparto las críticas a esta definición hechas por M. Bovero, La filosofia politica de Ferrajoli, en L. Gianformaggio (ed.), Le ragioni del garantismo, Giappichelli, Torino, 1993, p. 403ss.

${ }^{47}$ N. Bobbio, Il futuro della democrazia, p. 55.

${ }^{48}$ La noción de essentially contested concept es de W.B. Gallie, Essentially Contested Concepts, en M. Black (ed.), The Importance of Language, Cornell U.P., Ithaca-London, 1976, pp. 121-146. La democracia es tratada como essentially contested concept, además de por Gallie, también por ejemplo por W.E. Connolly, The Terms of Political Discourse, $2^{\mathrm{a}}$ ed., Martin Robertson, Oxford, 1974-1984, p. 10 y 29ss. En general dudo de que tal noción, a pesar de su fortuna, sirva para identificar una categoría de conceptos dotados de alguna especificidad semántica o pragmática; su utilidad analítica, me parece, solo es la utilidad, banal, de recordarnos que sobre algunos conceptos filosóficamente cruciales las disputas no terminan nunca. 
concepto dotado de un núcleo sólido mínimo (método de elección y decisión) no contestado, que representa una condición necesaria de cualquiera de sus usos. Ignorar este núcleo equivale a proponer una definición estipulativa de 'democracia' enteramente novedosa. Pero de una definición novedosa de democracia, por muy interesante que pueda ser, no se ve de momento su utilidad, al menos en filosofía.

Si lo anterior es cierto, resulta desconcertante la contraposición entre democracias que serían procedimentales y democracias que no lo serían; es desconcertante la crítica (y la defensa) de las definiciones y teorías de la democracia en cuanto que procedimentales (o no procedimentales). Democracia es (al menos, pero necesariamente) procedimiento (en el sentido arriba indicado), y sin procedimiento la democracia no es.

A decir verdad, a menudo se hace uso de la oposición entre definiciones procedimentales y no procedimentales para indicar de modo oblicuo una oposición bien distinta: la oposición entre definiciones mínimas y más que mínimas de 'democracia', o sea, entre definiciones que emplean un concepto de democracia circunscrito a su núcleo procedimental, y conceptos (o mejor, concepciones) de democracia que cualifican ese núcleo con ulteriores elementos. En efecto, muchas de las definiciones corrientemente etiquetadas como procedimentales estarían mejor calificadas como mínimas, para no dar ocasión a los malentendidos que pueden derivarse de la engañosa noción de procedimiento (véase supra).

La cuestión, la de si es preferible una definición mínima o bien más que mínima de 'democracia', tiene obviamente implicaciones vastísimas, y no se puede tratar seriamente en pocas palabras. Me limitaré a expresar concisamente mi (en absoluto original) opinión.

Por mi parte, me inclino a sostener que en filosofía política nos deberíamos limitar a utilizar un concepto mínimo de democracia, porque los significados que exceden de ese concepto mínimo son fuertemente controvertidos, y porque cargar el concepto de contenidos ético-políticos controvertidos produce inevitablemente el efecto de disfrazar de disputas sobre significados las disputas de fondo, de cuestiones analíticas las cuestiones sintéticas ${ }^{49}$. Valga aquí la enseñanza de Hart: las teorías no deberían construirse sobre las espaldas de las definiciones, si es que queremos mantenerlas abiertas a la refutación. Usar un concepto mínimo de democracia ofrece la ventaja de trasladar del terreno definitorio al terreno abiertamente normativo las disputas ético-políticas sobre el mejor sistema de gobierno. Los modelos más

\footnotetext{
${ }^{49}$ En este sentido véase, por ejemplo, F.E. Oppenheim, «Democracy - Characteristics Included and Excluded», en The Monist, 1, 55, 1971, pp. 29-50.
} 
que mínimos de democracia podrán ser cualificados con adjetivos: por ejemplo, hablando de democracia constitucional, mayoritaria, populista, liberal, etc., como suelen hacer los politólogos ${ }^{50}$.

Volviendo a Kelsen, veamos cómo, si no tiene sentido cualificar su concepto de democracia como procedimental (ya que todos lo son), también es dudoso que se pueda cualificarlo como mínimo, ni tampoco como concepto puramente normativo.

En efecto, Kelsen ciertamente habla de decisión de la mayoría, y de método, no de contenidos. Sin embargo, manifiesta numerosas incertezas y oscilaciones, que sus comentadores han hecho notar puntualmente, acerca de las relaciones entre democracia y liberalismo. Así, a veces admite que se podría seguir hablando de democracia incluso si la libertad individual fuese totalmente aniquilada, y otras veces afirma por el contrario que la democracia no puede separarse completamente del liberalismo, llegando incluso a sostener abiertamente que ambos coinciden ${ }^{51}$. Los derechos de libertad que él considera indispensables para la forma de gobierno democrática parecen ser algo más que el catálogo de los derechos que deberían constituir el presupuesto de la democracia entendida en sentido mínimo ${ }^{52}$.

Por otra parte, el concepto kelseniano de democracia tampoco es puramente normativo, ya que no mira sólo a las reglas del método, sino también al orden de la sociedad en la que el método ha de operar. Kelsen subraya repetidamente que la democracia presupone una cierta atmósfera social, una libertad de hecho y no sólo de derecho, una opinión pública libre para expresarse y activa al expresarse $\mathrm{e}^{53}$. Veremos más adelante cómo Kelsen se aleja del formalismo y del normativismo puro también en otros aspectos significativos.

\section{El nexo ausente entre constitucionalismo y democracia}

Está bastante acentuada hoy la tendencia a interpretar toda la obra de Kelsen como un corpus coherente, bien para subrayar la identidad de los

${ }^{50}$ Véase el interesante trabajo de D. Collier y S. Levitsky, «Democrazia con aggettivi. L'innovazione concettuale nella ricerca comparata», en Rivista italiana di scienza politica, 1997, pp. 449-476, donde se plantea el problema de la tasa de especificidad que deben poseer los conceptos de democracia elaborados a efectos de la investigación comparada.

${ }^{51}$ Para un examen de las incertezas de Kelsen sobre el tema, véase G. Pecora, Il pensiero politico di Kelsen, p. 15, 50ss., quien critica la calificación que da Kelsen de su propia concepción de la democracia como procedimental, calificación por lo demás oscilante; véase también R. Gatti, Pensare la democrazia. Itinerari del pensiero politico contemporáneo, A.V.E., Roma, 1989, p. 64.

${ }^{52}$ Para este catálogo, véase por ejemplo N. Bobbio, Il futuro della democrazia, p. 6.

${ }^{53}$ Kelsen, en la Teoria generale del diritto e dello stato (1945), tad. It. de S. Cotta y G. Treves, Etaslibri, Milano, 1994, p. 293, llega a afirmar que «una democracia sin opinión pública es una contradicción en los términos», y añade: «En la medida en que la opinión pública puede surgir donde estén garantizadas la libertad de pensamiento, la libertad de expresión, de prensa y de religión, la democracia coincide con el liberalismo político». 
presupuestos de la teoría pura y de la filosofía política kelseniana, bien para subrayar cómo la filosofía política de Kelsen impregna su teoría del Derecho.

Este enfoque interpretativo «holístico» se sustancia en una lectura también unitaria de las ideas kelsenianas sobre la constitución y la justicia constitucional, por un lado, y sobre el parlamentarismo y la democracia, por el otro. En este orden de ideas, se ha afirmado por ejemplo que «la teoría pura del derecho elaborada por Kelsen [...] puede ser interpretada como la doctrina jurídica de la democracia constitucional». Y además: «La teoría pura del derecho permite así formular los elementos fundamentales de una teoría constitucional de la democracia contemporánea, enunciando con claridad los términos de la relación existente entre democracia y derechos fundamentales» ${ }^{54}$.

Pues bien: esta interpretación a mí me parece inexacta.

En efecto, es cierto que Kelsen escribió, y además durante los mismos años, sobre democracia y sobre constitución, pero nunca produjo una teoría de la democracia constitucional, sino sólo, por separado, una teoría de la democracia, y una teoría de la constitución. Nunca elaboró una teoría de la democracia constitucional en el sentido de una concepción que afrontase expresa y sistemáticamente el problema de conciliar los dos polos en perenne tensión en el seno de este modelo: la soberanía popular y la constitución, la democracia y los derechos, la autonomía pública y la autonomía privada ${ }^{55}$.

No es que Kelsen ignorara esta tensión; pero lo cierto es que nunca la puso en el centro de sus reflexiones. Así, por ejemplo, él observa que el principio de la separación de poderes representa la negación de la soberanía popular, que quiere todo el poder en las manos del pueblo, pero esta observación está hecha, me parece, únicamente para señalar la distancia entre los ordenamientos políticos históricos y sus modelos ideales (la «metamorfosis» que los ideales sufren cuando descienden a la realidad), y no en cambio la divergencia entre los dos principios, el democrático y el constitucional ${ }^{56}$.

${ }^{54}$ G. Bongiovanni y G. Gozzi, Democrazia, en A. Barbera (ed.), Le basi filosofiche del costituzionalismo, Laterza, Roma-Bari, 1997, p. 236 y 237, cursiva de los autores.

${ }^{55}$ Uno de los (raros) pasajes en los que pone sobre el tapete este problema, es el siguiente: «Es importante darse cuenta de que el principio democrático y el principio liberal no se identifican, y de que, es más, existe entre ellos un cierto anatagonismo. En efecto, según el primero, el poder del pueblo es ilimitado [...] el liberalismo, en cambio, significa [...] también la limitación del poder democrático» (H. Kelsen, I fondamenti della democrazia, p. 196). Y más adelante, en la p. 245: «La democracia moderna no puede separarse del liberalismo político. $\mathrm{Su}$ principio es que el gobierno no debe interferir en ciertas esferas de intereses propios del individuo, los cuales han de quedar protegidos por la ley como derechos humanos fundamentales o derechos de libertad», si bien después, en el discurso que sigue, reconduce tales derechos a la tutela de las minorías.

${ }^{56}$ Véase H. Kelsen, Sociologia della democrazia, edición de A. Carrino, ESI, Napoli, 1991, p. 34; Id., Teoria generale del diritto e dello stato, p. 287. 
Más aún, uno de los problemas más críticos de las democracias constitucionales, el relativo a la «objeción contramayoritaria» suscitada por la judicial review, es tratado por Kelsen sólo tangencialmente, con la observación de que al final todo depende del modo en que se nombren los miembros del tribunal constitucional: la exigencia de garantizar la composición democrática del órgano de la justicia constitucional puede ser satisfecha fácilmente haciendo electivo el cargo ${ }^{57}$.

En general, la cuestión de la compatibilidad entre la garantía de los derechos fundamentales y la soberanía popular, que está en el centro del constitucionalismo democrático, viene afrontada por Kelsen de modo extremadamente conciso y seguramente insatisfactorio. En efecto, como es sabido, él se limita a sugerir que hay que evitar en las constituciones cualquier referencia a conceptos vagos que remitan a valores controvertidos, para conjurar la inevitable consecuencia del desplazamiento de poder del parlamento al órgano de la justicia constitucional y a los órganos de aplicación ${ }^{58}$. Incidentalmente, se puede observar que Kelsen teme el desplazamiento de poder del legislativo al judicial mucho más de lo que teme el desplazamiento de poder del constituyente al legislador. Este último desplazamiento puede de hecho ser neutralizado con el artificio clásico de la división de poderes aplicado al interior del poder legislativo mismo, o sea, separando el poder de hacer leyes del poder de controlarlas, atribuyendo éstos a dos órganos legislativos distintos. Kelsen en cambio no tiene especiales sugerencias que ofrecer para conjurar el traslado de poder del legislador a los jueces, más que la de reducir al máximo el grado de vaguedad de las normas constitucionales. Tal sugerencia no sólo resulta demasiado expeditiva y semánticamente ingenua (véase sin embargo infra), sino que también corta de raíz la razón de ser misma del constitucionalismo democrático, cuya máxima cuestión es precisamente la de cómo tutelar los derechos sin frustar la soberanía popular $^{59}$. Pero para Kelsen la constitución en sentido estricto o sustantivo es sólo el complejo de las reglas de la organización estatal, y el Estado de Derecho es simplemente el Estado regulado por el Derecho, no el Estado

${ }^{57}$ Véase H. Kelsen, Chi dev'essere il custode della costituzione?, en Id., La giustizia costituzionale, trad. it. de C. Geraci, Giuffrè, Milano, 1981, p. 284ss. El argumento de Kelsen es una réplica a Carl Schmitt, quien tachaba a los tribunales constitucionales de aristocráticos.

${ }^{58} \mathrm{H}$. Kelsen, La garanzia giurisdizionale della costituzione, en Id., La giustizia costituzionale, pp. 189-190. Id., Chi dev'essere il custode della costituzione?, p. 253ss.

${ }^{59}$ «El ideal republicano, que fue la primera forma del ideal democrático moderno, reposa de hecho sobre la asociación de dos temas, simultáneamente complementarios y opuestos: el del Estado de Derecho y el de las libertades públicas»: A. Touraine, L'idea democratica, en F. Crespi, R. Segatori (eds.), Multiculturalismo e democrazia, Donzelli, Roma, 1996, p. 149 (cursiva mía). 
vinculado por los derechos. Así pues, parecería completamente ausente en Kelsen uno de los lados de la tensión que atraviesa al constitucionalismo democrático contemporáneo: el lado de los derechos.

Kelsen quizá no tenía mucho que decir sobre esta cuestión; y quizá no fuera por casualidad que sus contribuciones acerca de la democracia se detuvieran hacia la mitad de los años cincuenta: los años en los que se afirma lo que se ha venido en llamar el paradigma constitucionalista ${ }^{60}$. Tal vez él no tenía mucho que decir por dos razones.

En primer lugar, porque, aunque es verdad que sus tesis democráticas penetran en su teoría pura del Derecho, también es verdad que la exigencia de pureza normativa penetra en sus reflexiones acerca de la democracia ${ }^{61}$. La democracia es un método de creación del ordenamiento, y el ordenamiento puede tener cualquier contenido: la exigencia de la pureza converge con la definición mínima de democracia.

En segundo lugar, la tensión inmanente en el constitucionalismo democrático está ausente en Kelsen porque, cabe sospechar, él en el fondo cultiva una idea latentemente integracionista de la sociedad y de la política, o por decirlo mejor, alimenta un confiado optimismo sobre la posibilidad de compromiso que la dialéctica entre mayorías y minorías consustancial al método democrático (¿necesariamente?) produce ${ }^{62}$. En este sentido, en la teoría kelseniana de la democracia encontramos atenuada y casi puesta en sordina la antropología pesimista-hobbesiana que para otros efectos cabe atribuir con justicia a Kelsen.

Así pues, en este aspecto Kelsen se mueve todavía de lleno dentro del horizonte del Rechtstaat decimonónico. La tensión entre derechos y democracia es extraña a su óptica y a sus preocupaciones. Él no parece darse cuenta de que el «paradigma» constitucionalista ha transformado irreversiblemente las constituciones, convirtiéndolas en necesario punto de confluencia de valores a menudo últimos y más a menudo aún controvertidos. $\mathrm{Su}$ sugerencia de evitar en el documento constitucional remisiones a la justicia, a la igualdad, a la equidad, y en general a valores controvertidos, en el

\footnotetext{
${ }^{60}$ Así lo llama L. Ferrajoli, «Diritti fondamentali», en Politica del diritto, 1998, p. 28.

${ }^{61}$ Como ilustra muy bien Carrino en su introducción a H. Kelsen, Sociologia della democrazia, op. cit.

${ }^{62}$ Por tanto, no me parece del todo correcto el diagnóstico de Gatti, Pensare la democrazia, p. 68: «la concepción procedimentalista de la democracia refleja, en el plano de la teoría política, el desencanto ya radical de una época, como la época de la que Kelsen es significativo intérprete, que parece haber perdido la fe en la posibilidad de cualquier acuerdo sobre valores comunes de convivencia y no está en situación de elaborar más alternativa que la constituida por el consenso sobre los 'universales procedimentales', última y descarnada expresión, diríase, de un bien común cuyo significado auténtico se ha ido perdiendo cada vez más».
} 
plano teórico puede considerarse que adolece de reduccionismo semánti$\mathrm{co}^{63}$; en el plano de los hechos, ha sido frustrada por el curso de la historia desde el momento en que se ha impuesto el modelo de las constituciones largas.

El modelo de Estado que Kelsen tiene presente es el de una organización normativa en la cual los valores y las verdades públicas no están predeterminadas ni siquiera genéricamente en forma de formulaciones de principios; en su modelo, más bien, los valores y los principios son creados y recreados en sede parlamentaria, mediante la confrontación entre mayorías y minorías y la praxis del compromiso ${ }^{64}$.

\section{Democracia sin derechos}

¿Qué interés puede tener, entonces, releer hoy al Kelsen democrático?

El interés viene dado precisamente por el hecho de que la composición entre esos dos elementos tan esenciales para nuestras democracias constitucionales está lejos de haberse realizado. Todos nosotros deseamos tener tanto la democracia como los derechos; el problema es cómo conseguir ambas cosas juntas, sin sacrificar una a la otra. La democracia, como sabemos, es una amenaza potencial para los derechos, en la medida en que la soberanía

${ }^{63}$ Llamo reduccionismo semántico a la convicción de poder influir sobre la vaguedad de un discurso simplemente sustituyendo los términos vagos por términos menos vagos (o viceversa). Además de querer ignorar la vaguedad de la distinción misma entre términos vagos y no vagos, hay que subrayar el alcance no general de esa tesis, que encuentra precisamente en el lenguaje jurídico un desmentido clamoroso. En efecto, en el Derecho la vaguedad del lenguaje no es tanto la causa, cuanto si acaso el producto de los conflictos interpretativos (que, especialmente en el caso de las normas constitucionales, son conflictos valorativos), y puede disminuir sólo si disminuyen tales conflictos. La vaguedad en el Derecho es por tanto una noción pragmática y no (sólo) semántica, y se encuentra en relación de proporcionalidad inversa respecto del consenso «cuajado» en los documentos jurídicos: crece con el decrecimiento de este último, y viceversa. Véase M. Jori, «Definizioni giuridiche e pragmatica», en Analisi e Diritto, 1995, pp. 109-144, quien extrae de esta consideración la conclusión de que el lenguaje jurídico tiene los rasgos pragmáticos de un lenguaje «administrado» por una autoridad. Para una reciente y perspicua formulación de esta idea con referencia a las disposiciones constitucionales, véase R.F. Nagel, Interpretation and Importance in Constitutional Law: A Re-assessment of Judicial Restraint, en J.R. Pennock, J.W. Chapman (eds.), Liberal Democracy, Nomos XXV, New York U.P., New York, 1983, pp. 181-207.

${ }^{64}$ Observa M. Fioravanti, Stato e Costituzione. Materiali per una storia delle dottrine costituzionali, Giappichelli, Torino, 1993, p. 143, a propósito de la concepción kelseniana de la constitución: «La constitución es pues en este sentido la norma fundamental de una sociedad máximamente abierta y pluralista, que escapa a toda definición sustantiva del bien común, así como a todo tipo de "homogeneidad" político-social que no sea la relativa al necesario reconocimiento y respeto de las reglas del juego. Por los mismos motivos, una doctrina de este tipo no nos dice nada acerca de los motivos por los que los diversos sectores sociales deberían ponerse de acuerdo; o mejor, nos dice que eso no es un capítulo del Derecho constitucional, sino de la política entendida como cálculo de conveniencias, de costes y beneficios». 
popular no esté restringida por límites. Los derechos, a su vez, son una amenaza para la democracia, tanto en el sentido de que representan una limitación de contenidos al libre despliegue de la soberanía popular, como en el sentido de que se confían a sí mismos - la determinación de su contenido y su tutela- a otros distintos del pueblo soberano, otros que podrían convertirse en los señores de los derechos, los administradores de su contenido y de sus confines.

Pues bien: en los escritos de Kelsen podemos encontrar implícitamente delineado un modelo de democracia constitucional sin derechos. La cosa puede sonar grotesca, y ha sido en efecto leída como una negación del espíritu del constitucionalismo democrático contemporáneo ${ }^{65}$. Kelsen consumaría esta traición en el momento en que reduce los derechos a sus garantías, o sea, respectivamente, a las obligaciones y prohibiciones correspondientes a las expectativas-derechos (garantías primarias), y a las sanciones previstas por las violaciones de tales expectativas (garantías secundarias). Con ello condenaría a la inexistencia jurídica en primer lugar precisamente a los derechos fundamentales sancionados en los documentos constitucionales, ya que por lo general es precisamente la formulación de estos últimos la que está desprovista de toda referencia a las garantías primarias y secundarias, cuya determinación viene así a ser demandada a los escalones posteriores del ordenamiento (o sea, principalmente a la buena voluntad del legislador). En este sentido, precisamente los derechos que deberían ser más fuertes y estar mejor garantizados, acaban por ser los más débiles y los menos garantizados: derechos de papel ${ }^{66}$.

A mí no me parece que ésta sea una buena crítica a Kelsen. De entrada diré que, si bien es efectivamente inaceptable la reducción kelseniana de los derechos a sus garantías secundarias (sanciones), la reducción de los derechos a las garantías primarias (obligaciones y prohibiciones) es en cambio necesaria y hasta imprescindible, ya que sin ella no se entendería en qué cosa puedan consistir los derechos ${ }^{67}$. Si el contenido de los derechos no puede ser reformulado en términos de obligaciones y prohibiciones a cargo de alguien, resulta incomprensible la definición misma del derecho como expectativa: «expectativa», en efecto, indica una relación, es siempre expectativa

\footnotetext{
${ }^{65}$ De modo particular, por Ferrajoli. Véase L. Ferrajoli, «Diritti fondamentali», esp. p. 9 y p. 23ss.

${ }^{66}$ La expresión, recogida por Ferrajoli, es de R. Guastini, «Diritti», en Analisi e diritto, 1994.

${ }^{67}$ La reducción de los derechos a garantías secundarias se hace necesaria en el modelo nomoestático kelseniano de la norma jurídica como juicio hipotético sancionador. Toda la obra de Kelsen está atravesada por la tensión no resuelta entre la perspectiva nomoestática y la nomodinámica, y es obviamente un fácil juego interpretativo denunciar las disonancias entre ambas.
} 
de algo, y este algo, para un derecho, no puede ser más que un comportamiento de otro normativamente prescrito como debido (o su omisión). No puede existir una expectativa sin aquello que se espera, igual que no puede existir, pongamos, una visión sin aquello que se ve. El anterior argumento es obviamente semiótico o definitorio, y no ontológico: no pretende obtener la existencia de las obligaciones a partir del concepto de expectativa, sino sólo subrayar que se trata de dos caras de la misma moneda.

Mientras que las garantías secundarias de los derechos son condición esencial de su efectividad (si aquéllas son a su vez efectivas, se entiende), las garantías primarias no son otra cosa que el contenido mismo de los derechos, visto desde el lado del sujeto pasivo.

La obligación, pues, no es otra cosa sino el contenido de los derechos. La reducción de los derechos a las garantías primarias operada por Kelsen, lejos de sancionar la «inexistencia» de los derechos constitucionales, comporta que se los lea inmediatamente como obligaciones a cargo del legislador $^{68}$. Existe después una garantía secundaria general de tales obligaciones, que es el control de constitucionalidad, y sorprende que esta crítica a Kelsen omita mencionar precisamente la técnica de tutela de los derechos sobre la que él concentró sus energías como teórico, o sea, la anulación de la norma que los viola por parte del tribunal constitucional.

Encuentro además inapropiado y teóricamente engañoso hablar de laguna técnica allí donde los derechos estén desprovistos de garantías primarias (es decir, donde las obligaciones del legislador estén insuficientemente determinadas) o secundarias (es decir, estén desprovistos de sanciones ulteriores respecto a la declaración de ilegitimidad constitucional). De laguna técnica en realidad sólo se puede hablar allí donde el Derecho positivo sea incompleto si se lo juzga iuxta propria principia (por ejemplo, si la constitución afirma que el derecho de huelga ha de ejercitarse sobre la base de las leyes que lo regulan, pero no se han dictado leyes que disciplinen el derecho de huelga).

${ }^{68}$ «Estas garantías constitucionales [o sea, los derechos y las libertades fundamentales] no son de por sí derechos subjetivos, ni simples derechos-reflejo ni derechos subjetivos privados en sentido técnico. Ellas se presentan como prohibiciones de violar (esto es, de abolir o limitar), por medio de leyes o de decretos con fuerza de ley, la igualdad y las libertades así garantizadas. Pero el elemento esencial de estas 'prohibiciones' no consiste en el hecho de que, a cargo del órgano legislativo, pueda ponerse el deber jurídico de no dictar tales leyes, sino en el hecho de que tales leyes, una vez en vigor, puedan ser anuladas mediante un procedimiento especial previsto para este fin, por causa de su "inconstitucionalidad'": H. Kelsen, La dottrina pura del diritto (1960), trad. it. de M.G. Losano, Einaudi, Torino, 1966, pp. 163-4. Unas páginas antes (p. 152), se lee que «la opinión tradicional, según la cual el derecho es un objeto de conocimiento jurídico distinto del deber y tiene clara prioridad respecto del deber, bien se puede reconducir a la doctrina iusnaturalista». 
La presunta laguna técnica es en realidad una insuficiencia de las obligaciones y de las sanciones previstas por el ordenamiento en tutela del derecho. Ese juicio de insuficiencia, sin embargo, no es teórico sino totalmente ético-político, y habría de presentarse abiertamente como tal, y por tanto la laguna debería calificarse más bien como laguna ideológica ${ }^{69}$. Que las garantías primarias estén diseñadas de manera vaga, o de algún otro modo insatisfactoria, equivale a una indeterminación del contenido de los derechos (indeterminación que a menudo, como sabemos, puede ser radical). Que las garantías secundarias sean incompletas o estén diseñadas de manera insatisfactoria o insuficiente, equivale a un déficit de tutela de los derechos.

Una situación, como la que caracteriza a muchos ordenamientos jurídicos contemporáneos, en la que los derechos sean altamente indeterminados (especialmente en cuanto a las obligaciones del legislador y de los demás poderes públicos) o estén insuficientemente tutelados (en cuanto a la sanción por su violación), puede sin duda juzgarse indeseable desde el punto de vista ético-político, pero no puede calificarse desde el punto de vista teórico como un caso de laguna del Derecho positivo. En realidad -conviene subrayarlo una vez más-, sólo se puede hablar de laguna cuando en el Derecho falte algo que debería estar, pero algo que podamos decir de antemano qué cosa es, sobre la base del mismo Derecho positivo. Sin embargo, no es éste el caso de las garantías (primarias y secundarias) de los derechos, como resulta evidente en cuanto nos hacemos las siguientes preguntas: ¿cuáles y cuántas obligaciones del legislador serían necesarias (¿o suficientes?) para colmar la laguna? ¿cuáles y cuántas sanciones serían necesarias (¿o suficientes?) para tutelar eficazmente el derecho? En el momento en que buscamos una respuesta a estas preguntas, se ve claramente que estamos discutiendo acerca de qué concreto contenido normativo debería tener el derecho, y acerca de qué concretas sanciones deberían establecerse para su tutela; estamos discutiendo de la semántica y no de la sintaxis de los derechos, y estamos discutiendo de semántica normativa, ya que la semántica descriptiva sólo puede proporcionarnos la descripción del contenido (vago) del derecho enunciado en la constitución.

La teoría no puede (ni debe) darnos contenidos precisos ni garantías eficaces: en un Estado democrático, sólo puede hacer esto el legislador democráticamente elegido. Contenidos y garantías podrán reputarse vacíos o incluso ilusorios, y entonces estará bien emprender una «lucha por los derechos»: bajo la forma de exigencia al legislador de leyes de tutela del derecho proclamado en la constitución, o bajo la forma de exigencia de en-

${ }^{69}$ El único juicio teórico, o mejor, descriptivo, puede ser el que se limita a ilustrar el contenido, normalmente vago, de la formulación del derecho. 
miendas constitucionales que formulen de modo más satisfactorio el contenido del derecho (o sea, las obligaciones del legislador). Sin embargo, sobre esa lucha, la voz del teórico (iuspositivista) no es una voz cualificada. La crítica de insuficiente tutela de los derechos, en efecto, presupone (no un modelo teórico-sintáctico sino) un modelo sustantivo de los derechos, es decir, un catálogo de derechos normativo y con contenidos, un catálogo que las constituciones contemporáneas no suministran (sino a grandísimas líneas) y presumiblemente nunca serán capaces de suministrar mientras persista el pluralismo de los valores que caracteriza a nuestras sociedades. En el plano político, la determinación de los contenidos de los derechos no podrá más que ser demandada, en el vago marco de las normas constitucionales, al pueblo soberano, o sea, al parlamento, al poder de reforma constitucional, o incluso al poder constituyente. Esto puede parecerle doloroso a quien albergue una justificada desconfianza hacia las asambleas parlamentarias, o hacia la sutileza de la opinión pública, pero resulta inevitable desde las reglas del juego democrático ${ }^{70}$.

Como alternativa al modelo kelseniano, se nos presenta un modelo de derechos teóricamente completo, y las enunciaciones de los derechos presentes en las constituciones como autosuficientes para predeterminar enteramente los contenidos normativos y las garantías que deberán disponerse para hacer no ilusoria la tutela de las proclamaciones constitucionales; suficientes hasta el punto de hacer inevitable un juicio de lagunosidad técnica del ordenamiento que no las establezca. El Derecho positivo parece tener así ya trazado el camino por el teórico, o por una constitución leída con las lentes del teórico, como documento que incorpora un catálogo -obviamente implícito ${ }^{71}-$ de contenidos normativos esculpidos con precisión en todos sus $\operatorname{aspectos}^{72}$.

${ }^{70}$ J. Waldron, Rights and Majorities: Rousseau Revisited, en J.W. Chapman, A. Wertheimer (eds.), Majorities and Minorities, Nomos XXXII, New York U.P., New York \& London, 1990, pp. 44-75, p. 71, observa que deberíamos tomarnos más en serio el elemento de insulto implicado por la tesis de que los ciudadanos y sus representantes son incapaces de hacer buenas leyes.

${ }^{71}$ No es casualidad que el ensayo de Ferrajoli sobre los derechos fundamentales, aquí citado varias veces, se cierre con una remisión a Dworkin, a quien ya otras veces se ha aproximado su pensamiento. Véase L. Gianformaggio (ed.), Le ragioni del garantismo, p. 35ss.; véase también S.C. Sagnotti, I diritti tra storia e morale. Riflessioni sul pensiero di Ronald Dworkin, Giuffrè, Milano, 1998, p. 119.

${ }^{72}$ Esto podría además considerarse un indicio de la presencia de una aporía en ese razonamiento, porque una de dos: o los derechos están ya completos en la constitución, y entonces obviamente no hay laguna técnica, o hay laguna técnica, pero falta el parámetro intranormativo con el que juzgar la pretendida laguna. 
Pero esos derechos «encontrados» por el teórico en la constitución acaban por parecer algo muy similar a los postulados de la razón.

Esto plantea antes que nada el problema de su justificación. ¿Cuál podría ser la justificación de derechos concebidos como prevalentes no sólo sobre el juego democrático-parlamentario, sino incluso sobre el mismo poder constituyente ${ }^{73}$ ? Estos derechos inatacables por considerarse inscritos en el mismo contrato social constitucional acaban por asemejarse irresistiblemente a los del viejo Derecho natural ${ }^{74}$. Naturalmente, este «prejuicio» hacia el Derecho natural podrá considerarse injustificado; pero siempre queda sin embargo el hecho de que «la validación filosófica y la autorización política son dos cosas completamente diferentes. [...] La autorización compete a los ciudadanos que se gobiernan a sí mismos en su comunidad. La validación compete al filósofo que razona por sí solo en un mundo habitado únicamente por él y lleno de los productos de sus especulaciones» ${ }^{75}$.

En segundo lugar, esto plantea el problema de su administración: los derechos, totalmente desvinculados de la soberanía popular, deberán no obstante ser administrados en su contenido y en sus implicaciones, en el cálculo de las garantías para su mantenimiento, que obviamente contribuyen a determinar el contenido y a delimitar los confines. Administración de los derechos, es decir, definición/redefinición de sus contenidos, elaboración de sus garantías: ¿a quién deberían corresponder todas estas tareas? La desconfianza hacia el legislador democrático y, en definitiva, hacia la política, impulsa irresistiblemente a confiarlas a los jueces, «dado que las discusiones internas en el poder judicial se asemejan de hecho mucho más que el debate democrático a los argumentos que se despliegan en la república ideal (en la mente del filósofo). Y parece plausible sostener que los derechos pueden ser definidos más correctamente mediante la reflexión de los pocos que mediante el voto de los muchos. [...] La lista filosófica de los derechos [...] pide una actividad judicial que es radicalmente intrusiva en lo que puede llamarse espacio democrático» ${ }^{76}$. El primado de las «listas filosóficas de los

\footnotetext{
${ }^{73}$ Como sostiene Ferrajoli, quien en su Principia iuris (en curso de publicación) defiende la tesis del agotamiento del poder constituyente en el acto de su ejercicio, y sostiene que el poder de reforma constitucional podrá ejercerse sólo en la dirección de la ampliación de los contenidos y de las garantías de los derechos ya recogidos en las constituciones.

${ }^{74}$ Que la constitución no coincida con el contrato social y no represente la base última de justificación de nuestras sociedades políticas, sino que requiera a su vez una justificación, está eficazmente argumentado por P. Railton, Judicial Review, Elites, and Liberal Democracy, en J.R. Pennock, J.W. Chapman (eds.), Liberal Democracy, Nomos XXV, New York University Press, New York, 1983, p. 154.

${ }^{75}$ M. Walzer, «Philosophy and Democracy», en Political Theory, 1981, p. 397.

${ }^{76}$ M. Walzer, «Philosophy and Democracy», pp. 390-1.
} 
derechos» se traduce inexorablemente en su encomendamiento a los jueces, y por tanto en una frustración de la democracia.

Kelsen debió haber visto bien todo esto, desde el momento en que, por desconfianza hacia el poder judicial, formulaba la sugerencia, cierto que naïf, de redactar las constituciones con rigor semántico.

Con su visión de la pacífica dialéctica parlamentaria orientada a la tolerancia y al compromiso, nos ofrece una indicación quizá inadecuada en su contenido (inadecuada especialmente para sociedades con un altísimo grado de conflictividad como las nuestras), pero todavía muy valiosa en el método: nos indica el espacio irrenunciable de la política. No es cristalizando los derechos en modelos teóricos aptos para medir las lagunas de los Derechos positivos, y confiándolos al terrible y no democrático poder judicial, como se maximiza su tutela. No es presumiendo que las «listas filosóficas de los derechos» están ya incorporadas en las constituciones, como se los concilia con la democracia. No es abandonando el espacio de la política en las manos del filósofo como se protegen ni los derechos, ni la democracia.

(Traducción de Juan A. Pérez Lledó) 